\title{
EXPANSÃO RECENTE DO SETOR SUCROENERGÉTICO E IMPLICAÇÕES TERRITORIAIS NA PECUÁRIA BOVINA: UMA AVALIAÇÃO NA REGIÃO DE ITUIUTABA (MG)
}

\author{
Matheus Eduardo Souza Teixeira ${ }^{1}$ \\ Mirlei Fachini Vicente Pereira²
}

Resumo: O objetivo deste artigo é avaliar as implicações territoriais da expansão recente da cana-de-açúcar sobre os espaços da pecuária bovina na MRG de Ituiutaba. O campo na região de Ituiutaba é marcado, historicamente, pela presença da pecuária bovina, afirmando-se como uma região tradicional nesta atividade. Recentemente, a região conhece, através de ações do Estado e da nova condição do setor sucroenergético no país, uma significativa expansão do cultivo da cana, afirmada pela inserção de três usinas, o que implicou em mudanças significativas na dinâmica da pecuária bovina. Para tal, identificamos três processos da expansão do setor sobre a pecuária na região de Ituiutaba: o deslocamento - quando pecuaristas arrendam a área e investem recursos em outros espaços-; a substituição - quando proprietários de terras desistem da atividade e arrendam as propriedades para o plantio de cana e também a coexistência (proximidade) da produção do setor sucroenergético e da pecuária bovina.

Palavras-chave: Setor Sucroenergético; Pecuária Bovina; MRG de Ituiutaba.

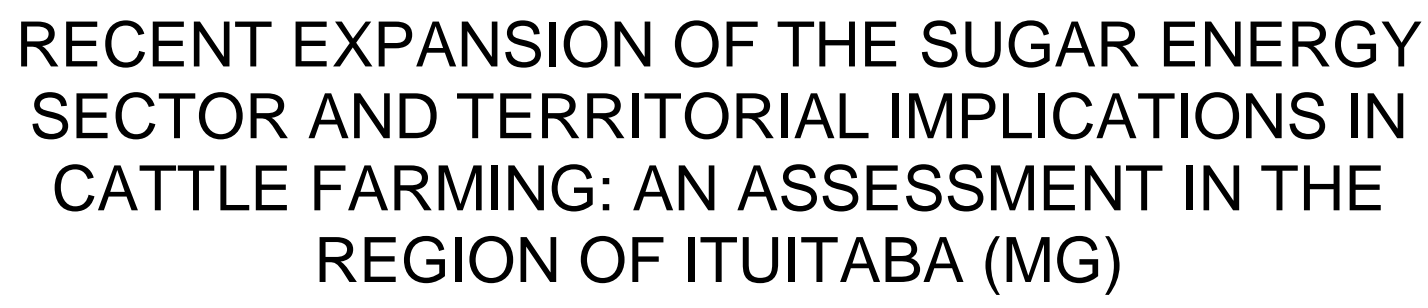

Abstract: The aim of this article is to assess the territorial implications of the recent expansion of sugarcane on the cattle ranching spaces in the MRG of Ituiutaba. The field in the region of Ituiutaba is historically marked by the presence of cattle raising, asserting itself as a traditional region in this activity. Recently, the region has experienced, through State actions and the new condition of the sugar-energy sector in the country, a significant expansion of sugarcane cultivation, confirmed by the insertion of three mills, which implied significant changes in the dynamics of cattle ranching. To this end, we identified three processes of the expansion of the sector on cattle raising in the region of Ituiutaba: displacement - when cattle raisers lease the area and invest resources in other spaces-; replacement - when landowners give up

\footnotetext{
${ }^{1}$ Doutorando em Geografia pelo Programa de Pós-Graduação em Geografia da Universidade Federal de Uberlândia (UFU). Email: matheuseduardo002@gmail.com

2 Professor Associado no Instituto de Geografia da Universidade Federal de Uberlândia (IG-UFU). Email: mirlei.ufu@gmail.com
} 
the activity and lease the properties for planting sugarcane -; and also the coexistence (proximity) of the production of the sugar-energy sector and cattle raising.

Keywords: Sugar-Energy Sector; Beef Livestock; Ituiutaba MRG.

\section{INTRODUÇÃO}

A pecuária bovina e a produção sucroenergética (cana-de-açúcar e derivados) apresentam-se como setores economicamente importantes, tanto ao longo da história do país, quanto na atual fase do período de globalização - açúcar e carne bovina sempre figuraram, na última década, entre os dez principais itens da pauta exportadora brasileira e representam algumas das máximas expressões do agronegócio e da condição subordinada do país na divisão internacional do trabalho.

O setor sucroenergético no Brasil é, historicamente, o maior produtor mundial de cana e também o maior exportador de açúcar. Neste início de século, o território nacional conheceu significativa expansão do cultivo da cana-de-açúcar, especialmente em função do aumento das demandas internacionais por açúcar e das possibilidades de afirmação do etanol como combustível renovável (fruto das preocupações com o aquecimento global no final do século $X X$ ), bem como da tecnologia flex fuelque hoje já compreende a maior parte da frota nacional de veículos. Além disso, o papel do Estado, através sobretudo de fartos financiamento do BNDES à juros baixos destinados ao setor (entre 1999 e 2015) teve enorme importância para desenvolvimento do setor sucroenergético no início do século atual, acompanhando o crescimento geral da exportação de commodities minerais e agrícolas, aposta do Estado brasileiro para a manutenção de superávits na balança comercial, mobilizando esforços políticos e induzindo certa reprimarização da pauta exportadora, processo que Delgado (2012) reconheceu como "novo pacto da economia política do agronegócio".

Diante do cenário favorável à expansão da cana-de-açúcar no território brasileiro, Sparovek, Maule e Burgi (2008) avaliam no final da década de 2000 que diversos seriam os efeitos da expansão dos cultivos da gramínea, reconhecendo tendências de uma ampliação dos canaviais em áreas próximas as já cultivadas, além de novas fronteiras de expansão sobre áreas predominantemente ocupadas por pastagens. Levando em conta o espectro possível dos impactos, os autores chamam a atenção para a necessidade de levarmos em conta as formas possíveis de expansão da cana-de-açúcar no espaço das atividades agropecuárias, apontando as seguintes modalidades: expansão por deslocamento, por competição, coexistência ou ainda com integração à demais atividades.

Reconhecendo tais dinâmicas e a conjuntura recente das atividades da bovinocultura e sucroenergética no país, a intenção do presente texto é avaliar os efeitos e implicações decorrentes da expansão recente da cana-de-açúcar em uma região tradicionalmente voltada à pecuária bovina, verificando a ocorrência dos processos de deslocamentos, competição ou coexistência das referidas atividades na Microrregião Geográfica (MRG) de Ituiutaba.

Inserida no Triângulo Mineiro, extremo oeste do estado de Minas Gerais, a MRG de Ituiutaba é formada por seis municípios: Ituiutaba (principal centro regional), Santa Vitória, Gurinhatã, Capinópolis, Cachoeira Dourada e Ipiaçu (Figura 1). 
Figura 1. Localização da Microrregião Geográfica de Ituiutaba - MG

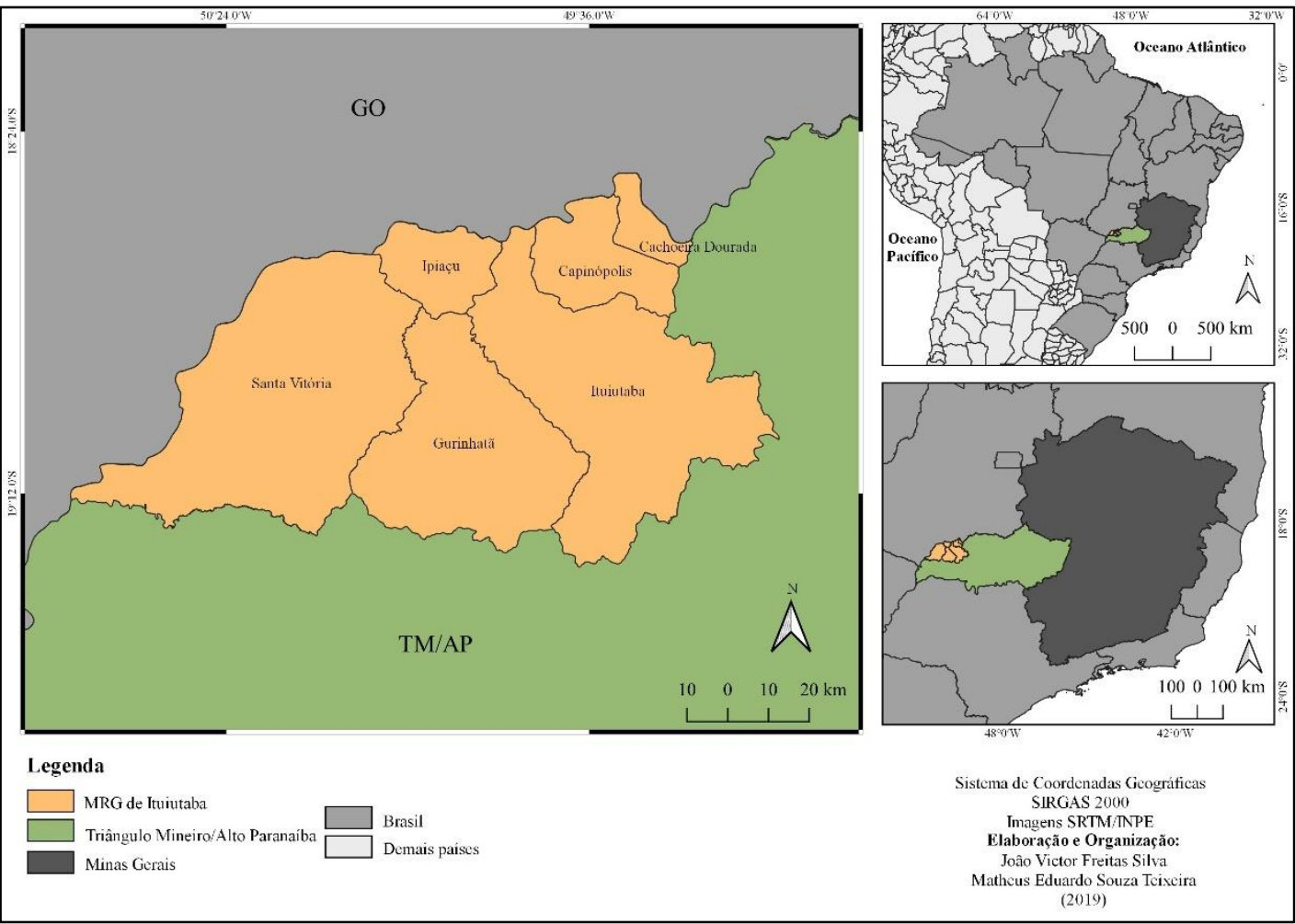

A MRG de Ituiutaba possui população estimada em 2016 de 152 mil habitantes, com PIB também registrado em 2016 de $R \$ 4,17$ bilhões (DATAVIVA, 2021). A microrregião possui importante efetivo de trabalhadores formais nas atividades voltadas aos setores de bovinocultura e sucroenergético, em 2017 , os trabalhadores formais eram, na sua totalidade, 29,7 mil empregados. Somados, os empregos na fabricação do açúcar e do álcool correspondem a 12,65\% do total de empregos formais na região. Já as atividades de criação de bovinos, abate de reses e fabricação de laticínios estão entre os sete ramos que mais participam no total de empregos da MRG de Ituiutaba, com 6,4\%, 3,4\% e 2,1\% respectivamente (DATAVIVA/RAIS, 2021), revelando o peso de ambas atividades na economia regional.

As exportações da MRG de Ituiutaba somaram U\$ 166 milhões de dólares em 2018, e foram exclusivamente oriundas dos gêneros agropecuários, liderado pela carne bovina congelada, com $\$ 96,3$ milhões de dólares. Os principais produtos exportados foram as carnes bovinas congeladas $(58,2 \%)$, álcool etílico $(13,2 \%)$, órgãos de animais (10,8\%), soja (6,5\%), milho (4,2\%) e açúcar in natura (3,6\%), indicando mais uma vez a dependência econômica do agronegócio na região (DATAVIVA/SECEX, 2021).

A região de Ituiutaba historicamente pratica a pecuária bovina de corte e de leite, afirmando-se como significativo espaço produtor desde o início do século $X X$, sendo até os dias atuais uma atividade importante na economia local. Recentemente a região fora acionada pelo setor sucroenergético que, em sua última vaga de expansão, tem ocupado cada vez mais a região com os cultivos de cana-de-açúcar e com a inserção de novas usinas sucroenergéticas desde o ano 2007, constituindo-se, de certo modo, como uma nova fronteira de expansão da cana em Minas Gerais.

Tal circunstância pode ser elucidada através de dados dos referidos setores na MRG de Ituiutaba, em que a área plantada de cana-de-açúcar aumentou de apenas 845 hectares em 1990, para mais de 88 mil no ano de 2019, avançando em grande 
parte sobre as áreas de pastagens (SIDRA/PAM, 2021). Em relação ao efetivo de bovinos, destaca-se que os números oscilaram entre 661 mil a 736 mil ao longo do mesmo período (1990-2019), enquanto que a produção de leite quase dobra, alcançando em 2019 mais de 130 milhões de litros (SIDRA/PPM, 2021).

Desta forma, analisar o uso do território pelas usinas sucroenergéticas atuantes na MRG de Ituiutaba nos permite avaliar possíveis relações e implicações territoriais entre o avanço da cana-de açúcar e suas consequências na pecuária bovina na região. Para tanto, a metodologia empregada foi composta dos seguintes procedimentos: a) levantamento bibliográfico temático, avaliando aspectos históricos e contemporâneos do setor sucroenergético e da pecuária bovina na MRG de Ituiutaba; b) coleta de dados secundários relacionados à agropecuária no recorte empírico de análise, a partir do Censo Agropecuário do IBGE; Sistema de Recuperação Automática (SIDRA); Instituto Mineiro de Agropecuária (IMA); Plataforma Data Viva; além de agentes agroindustriais da MRG de Ituiutaba (usinas sucroenergéticas, frigoríficos e laticínios). De modo complementar aos levantamentos de dados secundários, realizamos trabalhos de campo nos seis municípios que compõem a MRG de Ituiutaba, que consistiram em visitas e análises em propriedades rurais, instituições agropecuárias e em alguns agentes agroindustriais.

Para além desta introdução e das considerações finais, o texto é composto por duas seções. A primeira parte apresenta 0 contexto histórico/geográfico das atividades agropecuárias praticadas na MRG de Ituiutaba, enquanto a segunda seção avalia as implicações territoriais da expansão recente do setor sucroenergético na referida região.

\section{DA PECUÁRIA BOVINA TRADICIONAL À EXPANSÃO RECENTE DO SETOR SUCROENERGÉTICO}

A criação extensiva do gado bovino sobre os vastos campos originalmente cobertos pelo cerrado, ora ou outra cortados por imensas veredas, é traço que constitui marcadamente a paisagem do Triângulo Mineiro e, especialmente, da região de Ituiutaba (extremo oeste de Minas Gerais).

Para compreendermos o papel da pecuária bovina como atividade tradicional na região de Ituiutaba, faz-se necessário resgatar, brevemente, a formação e a consolidação dessa região. $O$ incipiente núcleo urbano que dá origem a Ituiutaba resulta da construção, no ano de 1820, de uma capela dedicada à São José, equipamento religioso que atendia a população que ocupava os cerrados da região (BARBOSA, 1995). Deste primeiro núcleo, origina-se a Freguesia de São José do Tijuco em 1839 (elevado à categoria de distrito) e, posteriormente, fora promovido à condição de vila, denominado como Vila Platina em 1901.

A área territorial do município de Vila Platina, em 1911, é exatamente a mesma porção territorial que hoje compõe o recorte da Microrregião Geográfica de Ituiutaba na classificação do IBGE, ou seja, é a partir desta porção territorial que surgem os demais municípios da atual microrregião, através dos processos de emancipação que ocorrem posteriormente.

Nesse sentido, é possível afirmar que a área que atualmente forma a MRG de Ituiutaba (MG) era, no final do século XIX e início do XX, composta por terras ocupadas com o objetivo da integração territorial, visando principalmente servir de ponto de apoio aos viajantes. Por isso, foi introduzida na região a pecuária bovina e o cultivo de 
pequenas lavouras de arroz e milho para subsistência e comercialização dos excedentes [...] (OLIVEIRA, 2013, p. 199).

Assim, enquanto o município de Uberaba se afirma como principal núcleo urbano e já com destacada função comercial no Triângulo Mineiro no final do século XIX e início do XX, a pecuária bovina permanece como principal alternativa econômica à região de Ituiutaba, principalmente pelo baixo dinamismo da rede de transportes que impedia o estabelecimento de trocas comerciais mais densas. Conforme aponta Carlos Brandão (1989, p. 40-41):

O restrito mercado interno regional, a incipiente rede de transportes e comunicações tanto intra-regional, quanto inter-regionalmente, contribuíram para que as oportunidades de expansão comercial fossem barradas, criando um isolamento entre as diversas "economias regionais" do Triângulo, Goiás e Mato Grosso. Ou seja, todas as possíveis alternativas de transação para os comerciantes triangulinos encontravam-se numa vida beirando a autarquia, fazendo da criação extensiva de gado sua principal atividade.

Entre os anos de 1920 e 1940, as atividades agropecuárias voltadas à comercialização realizadas no município de Ituiutaba eram basicamente três, destacando-se a criação de bovinos, a produção de arroz e de milho (Tabela 1), outras produções tinham caráter exclusivo de subsistência. Vale destacar que grande parte da população residia no campo, o que reforça o caráter rural do município até meados do século XX.

Tabela 1. População e produção agropecuária do município de Ituiutaba em 1920 e 1940

\begin{tabular}{c|ccc|cccc}
\hline \multirow{3}{*}{ Anos } & \multicolumn{3}{|c|}{ População } & \multicolumn{4}{c}{ Agropecuária } \\
\cline { 2 - 8 } & Sede & Rural & Total & $\begin{array}{c}\text { Bovinos } \\
\text { (cab.) }\end{array}$ & Arroz (t.) & Milho (t.) & Feijão (t.) \\
1920 & 1.992 & 18.780 & 20.772 & 133.274 & 1.979 & 10.447 & 552 \\
1940 & 1.424 & 33.628 & 35.052 & 202.038 & 2.304 & 18.005 & 702 \\
\hline
\end{tabular}

Fonte: IBGE - Recenseamento Geral (1920; 1940); Guimarães (2010).

Org. dos autores, 2021.

Esses fatores indicam uma economia essencialmente praticada no campo, sobretudo no que tange a criação de gado, que cresce 51,6\% em 20 anos. Neste período, a pecuária bovina apresentava-se como uma fonte de renda importante para Ituiutaba, conforme aponta Novais (1974, p. 32):

No início, e mais ou menos até a década de 1930, a economia do município girava, quase que totalmente, em torno da pecuária, pois a par das magníficas invernadas, bem assim, dos campos e cerrados como forragem natural com que foi dotado este município, era mesmo a principal atividade comercial de então, quando o fazendeiro, obedecendo à regra da época, criava e vendia o bezerro depois de desmamado, reservando as fêmeas no intuído de aumento do rebanho. Tal procedimento, que passou de geração a geração, embora seguro, permitia que a parte financeira se enfeixasse em poucas mãos, limitando assim a expansão e distribuição do dinheiro. 
Vale ressaltar que gêneros como o feijão e o arroz eram voltados para a alimentação humana, ao passo que o milho servia também para alimentação animal. Diante do cenário de criação e comercialização de gado bovino, importante função de todo Triângulo Mineiro para a época, o milho servia para complementação alimentar animal (OLIVEIRA, 2013), durante os períodos de estiagem típicos do Cerrado (meses de julho a setembro).

Deste modo, as atividades agropecuárias praticadas na região desde o século XIX já podem ser consideradas "tradicionais" na metade do século XX. Guimarães (2010, p. 93) aponta que o rebanho bovino predominava no Pontal do Triângulo Mineiro, ressaltando, no entanto, que o município de Uberaba possuía maior plantel, bem como uma melhor qualidade. Além de Uberaba, municípios como Ituiutaba, Prata, Patrocínio e Frutal contavam com expressivos rebanhos bovinos.

Ganhando maior expressão na região, a década de 1940 marca a inserção, no município de Ituiutaba, de unidades industriais para o beneficiamento dos produtos oriundos da criação de gado, tanto no que diz respeito ao leite, quanto a carne. Desta forma, dois laticínios (produção de manteiga) se instalam no final da década de 1930, processando a produção de leite na região e reforçando as atividades pecuárias, conforme apontou Vilela (2001):

[...] Alguns leiteiros abasteciam a cidade de leite "in natura". Os fazendeiros reservavam algum leite para fazer queijos, mas em sua maior parte, era desnatado, destinando-se o "soro" (leite desnatado) aos porcos e o creme às indústrias de manteiga: "Fazendeira" (1938) de Antônio Baduy e "Invernada" (1940) de Farjala Miguel Jacob (VILELA, 2001, p. 89).

Além dos laticínios, um frigorífico, o Matadouro Industrial de Ituiutaba S.A. (MIISA), se instala em Ituiutaba na década de 1940, com capacidade de abater 400 cabeças de bovinos e 500 cabeças de suínos diariamente, transformando a região em um grande centro de abate de animais.

A situação regional começa a ganhar novas características em meados do século XX. O incremento da população em demais cidades do Triângulo Mineiro (especialmente Uberaba), e a própria urbanização que aos poucos se fortalece no Brasil e particularmente no estado de São Paulo, garantem mercado para a produção agropecuária praticada no Triângulo Mineiro.

As décadas de 1950 e 1960 apontam incremento discreto da produção regional de cereais como arroz e milho, e a pecuária ainda figurava como importante atividade produtiva na região, sobretudo no município de Ituiutaba, ganhando notoriedade no estado e no país, conforme destacado em publicação do IBGE:

A atividade pecuária tem alta expressão econômica, sendo Ituiutaba um dos grandes centros de criação de gado vacum, suíno e equino do Estado, gado esse não só exportado, mas também abatido, concorrendo para a indústria de produtos alimentares. Em relação aos suínos, convém notar que poucos municípios mineiros apresentavam número superior a 50.000 cabeças. Ituiutaba, pois, com cerca de 120.000 cabeças, apresenta-se com realce no quadro estadual (IBGE, 1959, p. 307).

É na metade do século $X X$ também o período em que a vasta porção territorial do município de Ituiutaba paulatinamente conhece um processo de divisão político administrativa, dando origem, a partir de antigas povoações e distritos, a emancipação 
dos municípios de Santa Vitória (1948), Capinópolis (1953), Cachoeira Dourada (1962), Gurinhatã (1962) e Ipiaçu (1962), todos compondo a atual MRG de Ituiutaba.

A pecuária mantém parte das suas atividades voltadas para a produção de leite na região de Ituiutaba, que serviu, também, para atender a demanda dos laticínios presentes no município desde a década de 1930.

Entre as décadas de 1950 e 1960, a pecuária bovina na região de Ituiutaba, tanto a voltada para o corte, quanto a leiteira, se desenvolvia de forma extensiva, com baixo emprego técnico e em geral pouco capitalizada (OLIVEIRA, 2013, p. 240). De acordo com o IBGE (1959), a região de Ituiutaba comercializava seu rebanho bovino com os municípios de Uberlândia/MG, Barretos/SP e São José do Rio Preto/SP.

Vale mencionar que, na década de 1950, o cultivo de arroz ganha importância na região, com predominância do município de Ituiutaba. Tal cultivo salta de pouco mais de duas mil toneladas na década de 1940 para 47 mil toneladas em 1950, nesta década foram cultivados mais de 25 mil hectares de arroz em toda a região de Ituiutaba (IBGE, 1940; 1950). Desta maneira, várias indústrias de beneficiamento de arroz se instalaram em Ituiutaba, o que lhe rendeu o título de Capital do Arroz ${ }^{3}$.

Desta forma, a pecuária bovina, juntamente com a agricultura, norteou as atividades de Ituiutaba a partir da década de 1940, contribuindo para o processo de industrialização do município, como aponta Chaves (1971, p. 48):

O gado bovino ocupa ainda o primeiro lugar nas estatísticas mineiras e fornece leite para duas fábricas de manteiga. Uma charqueada abate e industrializa a produção de bois engordados nas pastagens mais distantes do vale. Enfim, é a indústria aliada à pecuária e à agricultura, é a industrialização "in loco" de toda produção do município [...].

Apesar da importância econômica das atividades agropecuárias até meados do século XX na região de Ituiutaba, é somente a partir dos anos 1970 que tais atividades incorporam aspectos modernizadores. Tais circunstâncias acompanharam a modernização agropecuária brasileira, através da expansão de novos cultivos de grãos nos cerrados do Brasil Central.

Especialmente no Cerrado, projetos do Estado foram essenciais para a inserção de vastas regiões à moderna dinâmica da agricultura voltada à produção agroindustrial. O POLOCENTRO visava o desenvolvimento da agricultura nas áreas de Cerrado, influenciando diretamente a região de Ituiutaba no final de década de 1970. Avaliando a produção agropecuária regional do referido período, Vilela (2001, p. 93) relata que, em Ituiutaba, "[...] as braquiárias chegaram e, com elas e o POLOCENTRO, a definitiva ocupação dos campos e cerrados para fins agrícolas e pecuários".

O processo de modernização na década de 1970 não se restringiu apenas à agricultura, mas também à pecuária bovina, sobretudo a leiteira, com a intensificação das atividades realizadas pelos laticínios da região de Ituiutaba. Enquanto a década de 1960 revelava uma produção de pouco mais de sete milhões de litros, o ano de 1970 apresenta forte crescimento, alcançando cerca de 11 milhões de litros, produção esta que conhece significativa expansão em 1980, atingindo mais de 61 milhões de litros ${ }^{4}$.

\footnotetext{
${ }^{3}$ [...] Em 1950 Ituiutaba já era a maior produtora de arroz e de milho em todo o Estado de Minas Gerais, com cerca de 10.000 alqueires (mineiros) de arroz sendo cultivados, rendendo-lhe o título de "capital do arroz" (SILVA, 1997, p. 25-26).

${ }^{4}$ Vale destacar que o número de vacas ordenhadas salta de 42 mil em 1970 para 83 mil em 1980 (IBGE, 1970; 1980). A produtividade média do rebanho leiteiro também aumenta substancialmente, passando de 266 litros por vaca no ano de 1970 , para 738 litros/vaca no ano de 1980.
} 
Tamanha é a produção regional de leite que, no ano de 1973, inaugura-se uma filial do laticínio Catupiry no município de Santa Vitória. Em 1976, é instalada em Ituiutaba uma unidade industrial da multinacional suíça Nestlé, além disso, ocorre no mesmo período a ampliação das atividades do laticínio Baduy e Cia (estabelecido desde 1938). Tal é também a condição para um novo reforço e modernização da pecuária leiteira regional ao longo dos anos 1970 e 1980.

Da década de 1970 para 1980 também ocorre crescimento expressivo do efetivo bovino na região de Ituiutaba, que dobra de tamanho, saltando de 346 mil para 702 mil cabeças (IBGE, 1970; 1980).

Ressalta-se que, a bovinocultura, neste período, também conhece um processo de modernização, através das práticas de plantio de pastagem (Gráfico 1), com o objetivo de expandir as áreas para criação do rebanho bovino e, sobretudo, para o ganho de produtividade da atividade.

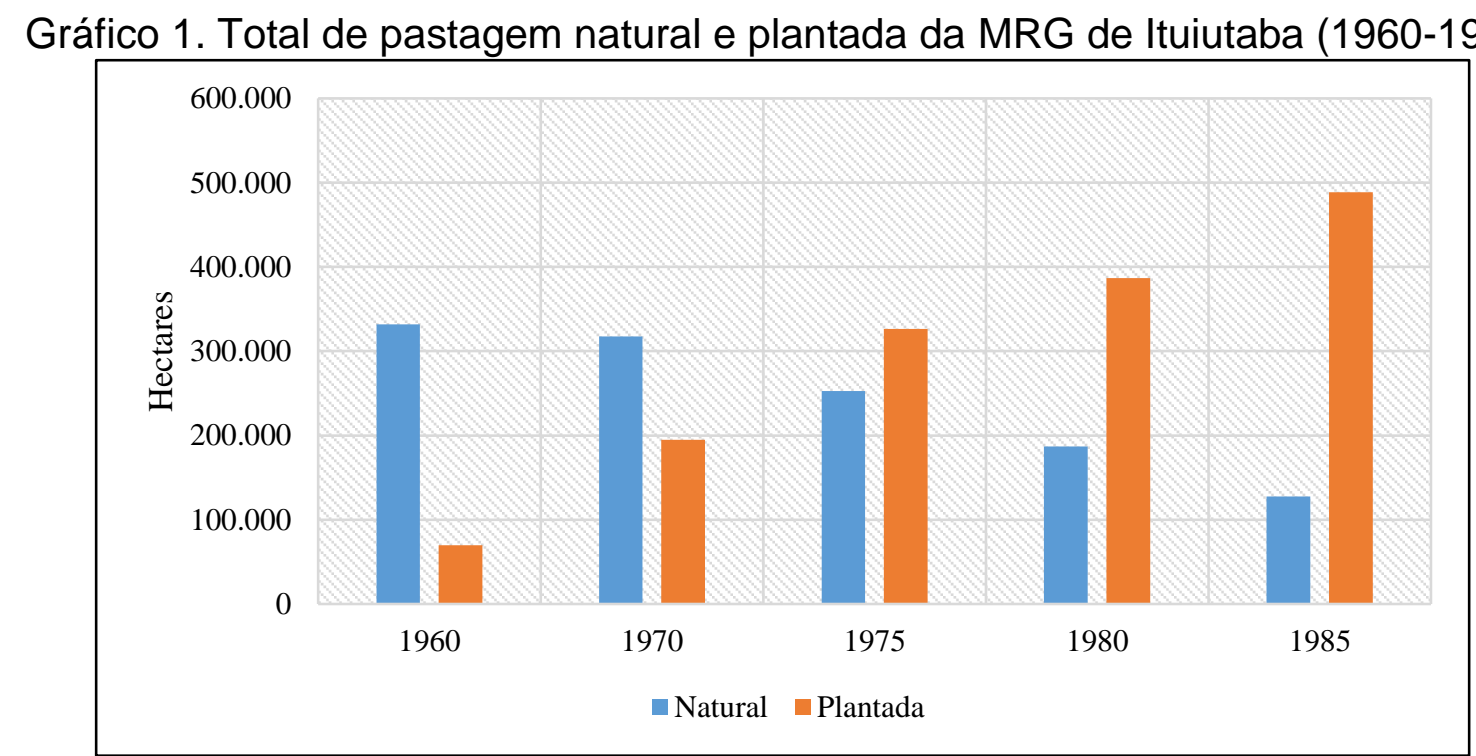

Fonte: IBGE - Censo Agropecuário (1960; 1970; 1975; 1980; 1985). Org. dos autores, 2021.

Comparando o ano de 1970, período que se acentua o processo de modernização, com o ano de 1985, observa-se que as áreas de pastagens naturais sofrem um declínio de aproximadamente $44 \%$, enquanto que as áreas de pastagens plantadas crescem em torno de $88 \%$ na região.

No que se refere à modernização da agricultura, a novidade para os cultivos é sem dúvida a inserção da soja ${ }^{5}$, na medida em que cultivos tradicionais como o arroz perdem espaço na região. Neste sentido, no final do século XX a MRG de Ituiutaba, assim como todo o Triângulo Mineiro, conhecem significativa ampliação no cultivo de grãos, especialmente a soja, decorrente, sobretudo, de políticas públicas de modernização e expansão da agricultura no Cerrado, a partir das décadas de 1970 e 1980

Assim, o cultivo da soja, mais que dobra sua área plantada de 1980 para 1990, movimento que também ocorre no ano 2000 , aumentando também mais que o dobro

\footnotetext{
${ }^{5}$ Os incentivos governamentais para a modernização da agricultura no território nacional e a consolidação do POLOCENTRO (CLEPS JUNIOR, 1998), garantiram a inserção de forma significativa da soja na região de Ituiutaba em curto espaço de tempo, com mais de cinco mil hectares em 1980.
} 
em relação a 1990. No decorrer dos anos a soja aumenta sua extensão, alcançando 72 mil hectares na MRG de Ituiutaba em 2019 (SIDRA/PAM, 2021).

Para além da expansão dos cultivos de soja na microrregião de Ituiutaba, percebe-se, também, o aumento dos coeficientes de produção na pecuária bovina a partir de 1980, seja a de leite ou de corte. O aumento nos índices de pecuária bovina também é acompanhado por um processo de modernização e intensificação da produção, condições estas que estão atreladas à "nova natureza científica da produção que alcança o campo moderno e redefine a pecuária nacional, tornando-a científica e, ao mesmo tempo, globalizada" (PEREIRA, 2012a, p. 18), visto os esforços empreendidos, seja para a conquista de novos mercados por agentes que passam a atuar na escala global, seja pelos aspectos da criação dos animais, cada vez mais orientada por técnicas e procedimentos elaborados externamente.

O contexto de permanência das atividades ligadas à pecuária e também a moderna agricultura de grãos, que marca a região no final do século $X X$, será transformada no início do século XXI, a partir de uma nova vaga de expansão e modernização da produção sucroenergética no Brasil, processo este que também alcança o Triângulo Mineiro (PEREIRA, 2012b).

Atualmente, a região de Ituiutaba apresenta grandes extensões de soja e canade-açúcar, além de altos índices de pecuária bovina. Entretanto, a expansão da canade-açúcar resultou em transformações na pecuária bovina, conforme avaliamos a seguir.

\section{AS IMPLICAÇÕES DA EXPANSÃO RECENTE DO SETOR SUCROENERGÉTICO NOS ESPAÇOS DA PECUÁRIA BOVINA DA MRG DE ITUIUTABA}

$\mathrm{Na}$ MRG de Ituiutaba o efetivo do rebanho bovino oscila ao longo dos anos, mantendo-se de certo modo estável nas últimas duas décadas - eram 718 mil cabeças em 2000, 693 mil em 2010 e 725 mil cabeças em 2019 (SIDRA/PPM, 2021). No que tange à pecuária de corte, ressalta-se que a taxa de lotação (cab./ha) tem aumentado cada vez mais na MRG de Ituiutaba, isto é, o manejo do gado ocorre progressivamente em maiores quantidades de cabeças em espaços menores, indicativo de modernização da atividade e, segundo nossa hipótese, também resultado da competição por espaço, haja visto a expansão da agricultura moderna no espaço regional. Em 2000 a taxa de lotação da MRG de Ituiutaba era de 1,29, aumentando para 1,56 em 2010 e 1,83 cab./ha em 2019 (LAPIG/UFG; SIDRA/PPM, 2021).

A produção de leite na MRG de Ituiutaba também aumentou constantemente a partir de 1980 . No século atual, a produção de leite na região está atrelada às modernas práticas, fato que implicou em grandes índices de produtividade. Em termos de volume, a quantidade aumenta de 84 milhões em 2000 para 108 milhões de litros de leite em 2010, produção esta que alcança 130 milhões em 2019. Em termos de produtividade, o crescimento é ainda mais expressivo, saltando de mil litros/vaca em 2000 para 2,8 mil litros/vaca em 2019 (SIDRA/PPM, 2021).

Atualmente, a MRG de Ituiutaba conta com sete principais agentes industriais que coordenam as atividades da pecuária bovina. Os laticínios Baduy e Cia, Nestlé e Canto de Minas, todos localizados em Ituiutaba; além do Catupiry e Bela Vista, estabelecidos no município de Santa Vitória. Quanto aos frigoríficos, duas grandes unidades estão instaladas, o JBS e o Frig' West, ambos localizados no município de Ituiutaba. 
No entanto, uma nova dinâmica territorial e produtiva se configura no setor sucroenergético brasileiro a partir da década de 2000 (CASTILLO, 2015) marcada por significativa expansão da produção, para a qual contam um conjunto de fatores externos tais como o aumento da demanda internacional e dos preços das commodities agrícolas, incluindo o açúcar; os compromissos assumidos pelo Brasil e demais países para a redução da emissão de gases do efeito estufa no Protocolo de Kyoto (1997), fazendo surgir um cenário otimista para o etanol (o que poderia the render a condição de uma nova commodity), como alternativa aos combustíveis fósseis. No país, e como fatores internos, o desenvolvimento da tecnologia flex fuel para automóveis (a partir de 2003 e hoje já compondo a maior parte da frota nacional), além de abundantes financiamentos públicos (via BNDES), figuraram como suporte à expansão do setor.

Assim como com em outras partes do território nacional (notadamente a região do Cerrado), o Triângulo Mineiro de modo geral e particularmente a região de Ituiutaba são acionados no processo de expansão do setor sucroenergético, sendo que, atualmente, três usinas se encontram em funcionamento na MRG de Ituiutaba - uma inserida no município de Santa Vitória (usina Santa Vitória - início das atividades em 2008), uma no município de Capinópolis (usina Vale do Paranaíba ) e outra localizada no município de Ituiutaba (usina BP Bunge ${ }^{6}$ ), responsáveis pelo beneficiamento de quase toda a produção de cana-de-açúcar da microrregião.

Desta forma, a produção de cana fora conduzida a partir da inserção das usinas sucroenergéticas na região, sendo que tal produção ganha expressividade a partir de 2007, com 23 mil hectares de cana cultivados na MRG de Ituiutaba. Conforme vão se inserindo as usinas, a produção intensifica, e a área de cultivo de cana salta de 68 mil em 2010 para 88 mil hectares em 2019, na microrregião (SIDRA/PAM, 2021), situação que é melhor compreendida através da figura 2.

\footnotetext{
${ }^{6} \mathrm{~A}$ usina BP Bunge surge com a joint venture entre a Bunge e a BP em 2019. No entanto, a BP atuava desde 2011, que por sua vez, comprou as benfeitorias da antiga usina CNAA que operava no município desde o ano 2007 (ESTADÃO, 2011).
} 
Figura 2. Evolução temporal das áreas de pastagens e de cana-de-açúcar na MRG de Ituiutaba (1990-2018)

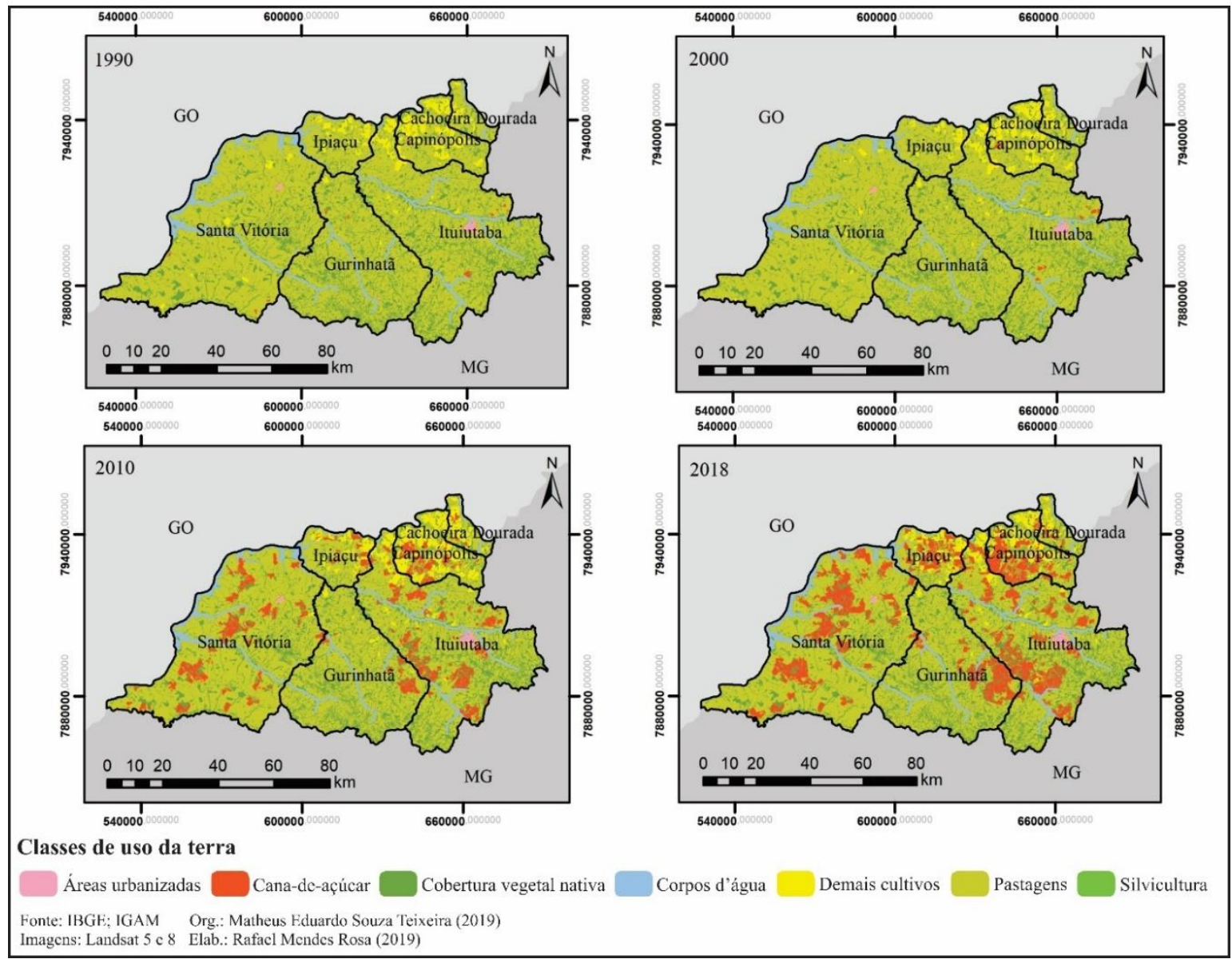

Assim, a forte expansão do setor sucroenergético na MRG de Ituiutaba resultou em implicações territoriais, como o deslocamento de atividades de pecuária bovina para outras regiões e estados, a substituição de propriedades de pecuária bovina para as atividades de cana-de-açúcar, mas também a coexistência dessas atividades e mesmo exigências de modernização e de aumento da produtividade à pecuária bovina que permanece na região.

De modo geral, a inserção das atividades sucroenergéticas em áreas prioritariamente de pecuária bovina extensiva pode ocorrer por esquemas de substituição, deslocamento, integração ou coexistência, conforme aponta o trabalho de Sparovek, Maule e Burgi (2008). O processo de substituição ocorre quando a atividade da propriedade, em sua totalidade, é alterada em função de outra prática. $O$ deslocamento, como o termo sugere, implica na transferência de atividades para outras localidades. A coexistência consiste na proximidade da realização de duas atividades, podendo ser em propriedades distintas ou numa mesma propriedade, em que o manejo das ações é elaborado de forma separada (o que não significa que em termos econômicos elas não sejam complementares). No que concerne à integração, a mesma baseia-se no desempenho de duas atividades de forma combinada, isto é, quando uma atividade participa e agrega elementos ou fatores à outra (no caso estudado, um exemplo de integração seria o dos subprodutos da cana empregados, por exemplo, na alimentação do gado). 
$\mathrm{Na}$ região de Ituiutaba a expansão da produção canavieira ocorreu principalmente, a) por meio de deslocamento - com pecuaristas arrendando áreas e investindo recursos em novos espaços (tanto para a pecuária com maior emprego técnico, quanto para a extensiva); b) por substituição - com proprietários de terras (em geral antigos pecuaristas), desistindo da atividade e arrendando as propriedades para o plantio da cana -; e c) também pela coexistência (proximidade) da produção sucroenergética e da pecuária bovina em propriedades distintas. Em menor grau, há ocorrência de coexistência em uma mesma propriedade - com latifundiários arrendando parte de suas propriedades e investem tais recursos na pecuária bovina (na maioria das vezes com caráter intensivo e modernizado, na mesma propriedade). Destaca-se que a coexistência ocorre também como uma condição das características físicas da propriedade, uma vez que nem toda a área é passível de mecanização (como é o caso das "terras dobradas", em terrenos de maior declividade), condicionando o proprietário/produtor à utilização deste espaço para a pecuária bovina. Ressalta-se que, tanto através das incursões em campo, quanto pela coleta de dados e informações secundárias, não encontramos registro de integração das atividades de cana e pecuária bovina na região de Ituiutaba.

$\mathrm{Na}$ MRG de Ituiutaba, a expansão da lavoura de cana-de-açúcar ocorreu, sobretudo, sobre os espaços ocupados por rebanhos de corte, deslocando deste modo a atividade para outras áreas. No decorrer dos trabalhos de campo, através de relatos recolhidos em instituições ligadas às atividades agropecuárias (Sindicatos dos Produtores Rurais, Emater e IMA), bem como diretamente de produtores rurais, constatamos que a pecuária bovina na região, em meados do século $X X$, era desenvolvida de forma simples, com o gado solto nos extensos campos de cerrado, sendo que esses animais, em um dado momento, eram comercializados para o frigorífico local de Ituiutaba. Um significativo número dos proprietários que mantinham de certo modo tal prática era oriundo de outros estados do país, o que de certo modo facilitou o deslocamento dessa atividade.

Nesse contexto, ao arrendar as áreas de pastagens para o setor sucroenergético, parte dos pecuaristas da região migraram para outras localidades, principalmente para áreas com terras mais baratas, mecanismo muito parecido com o que se encontra em outras regiões do país, conforme apontam os autores:

As razões para isso são diversas, mas se relacionam principalmente com a valorização do preço da terra e com o caráter extensivo da produção, da maior parte da pecuária. Com as terras valorizadas e a possibilidade de produção agrícola intensiva mais eminente (maior rentabilidade), o custo de arrendamento se eleva, deslocando os pequenos arrendatários para regiões mais favoráveis (com menor custo de arrendamento). Os grandes produtores se veem atraídos a vender ou arrendar suas terras e transferir seus negócios para regiões mais remotas, em que há real possibilidade de expansão da produção, preservando seu caráter extensivo (SPAROVEK; MAULE; BURGI, 2008, p. 85).

Desta forma, e pelas informações coletadas em campo, evidenciamos que, na região, ocorrera o deslocamento das atividades pecuária bovina extensiva para outros estados, principalmente Goiás, Mato Grosso, Tocantins e Pará, como decorrência da inserção das monoculturas e especialmente pelo recente ingresso da cana-de-açúcar.

Quanto a substituição de propriedades rurais voltadas à pecuária bovina por propriedades com arrendamento/parcerias para a produção de cana-de-açúcar para 
as usinas sucroenergéticas, tal processo justifica-se pelas vantagens econômicas deste, em detrimento das incertezas de lucro da pecuária bovina, bem como dos altos custos de sua produção, como também nos fora relatado em campo.

A tabela 2 expõe a quantidade de estabelecimentos agropecuários da MRG de Ituiutaba com atividades voltadas para a pecuária bovina (gado de corte e leite) e para - cultivo de cana, direcionados para atender as demandas das unidades sucroenergéticas, ou seja, não são contabilizadas as propriedades que produziam cana para alimentação de gado e/ou para produção de cachaça, rapadura e outros derivados.

Tabela 2. Propriedades de pecuária bovina e de cana-de-açúcar da MRG de Ituiutaba nos anos de 2006 e 2019

\begin{tabular}{lcc}
\hline Propriedades Rurais & 2006 & 2019 \\
\hline Pecuária bovina & 3.529 & 3.319 \\
Cana-de-açúcar & 78 & 512 \\
\hline Total & 3.607 & 3.831 \\
\hline
\end{tabular}

Fonte: IBGE - Censo Agropecuário (2006); IMA (2019); Agentes/trabalho de campo (2019). Org. dos autores, 2021.

Nota-se que as propriedades rurais com práticas de pecuária bovina predominam na região. No entanto, comparando o ano de $2006 \mathrm{com} 2019$, percebese uma queda de 210 unidades voltadas para a bovinocultura, ao passo que, nesse período, verifica-se um aumento significativo nas propriedades voltadas ao cultivo de cana-de-açúcar (434 unidades). Os dados sugerem que pelo menos $41 \%$ das propriedades com cana-de-açúcar na MRG de Ituiutaba eram, anteriormente, dedicadas à pecuária bovina, e que tais unidades tiveram suas atividades substituídas a partir da expansão das atividades do setor sucroenergético, a partir de 2007 na região.

Fora constatado em campo - através de visitas em propriedades rurais, bem como com a partir de consultas aos sindicatos de produtores rurais -, que os proprietários que detêm mais de uma propriedade rural concentraram as atividades de pecuária bovina em uma delas - intensificando a produção -, sendo que as demais propriedades em geral são voltadas ao arrendamento para o cultivo da cana, aumentando assim os seus rendimentos, condição esta que, em geral, também potencializou a modernização da prática de pecuária bovina (com investimentos em genética, infraestruturas e manejo da criação).

Para Sparovek, Maule e Burgi (2008), a principal dinâmica das áreas de expansão do setor sucroenergético está relacionada, portanto, ao deslocamento e à substituição de outras produções, com amplos proveitos para os canaviais dominarem a paisagem. Quanto mais próximas as usinas sucroenergéticas, maior a tendência de um "mar de cana" - dominando a paisagem regional, processo este também identificado por Castillo (2015) em função das características intrínsecas ao setor, como a necessária proximidade entre canaviais e usinas processadoras, dado as características de perecibilidade da cana e altos custos de transporte da matériaprima. A necessidade do cultivo da cana-de-açúcar em grande escala e num raio próximo às unidades sucroenergéticas é, deste modo, uma implicação inevitável, levando a certo "engessamento" do território (CASTILLO, 2015).

Apesar de apresentar poucos casos na área em estudo, a coexistência das atividades em uma mesma propriedade tornou-se uma alternativa para donos de terras que utilizam a receita dos arrendamentos/parcerias para intensificarem as atividades de pecuária bovina, bem como para propriedades que, devido às suas 
características físicas, são inaptas para o cultivo da cana-de-açúcar em toda extensão do estabelecimento.

Com a escolha pelo arrendamento/parceria de terras para as usinas sucroenergéticas, o proprietário/produtor pôde aumentar sua renda e consequentemente se profissionalizar no manejo da pecuária bovina, com uma nutrição animal a base de ração, melhoramento genético do rebanho, confinamentos, maquinários, etc. Neste caso, as áreas de pastagem diminuem, mas a atividade, no entanto, é modernizada, com intensificação da produção e aumento da produtividade.

Constatou-se em campo representações de coexistência das atividades de pecuária bovina e arrendamento/parceria de terras para as usinas sucroenergéticas na MRG de Ituiutaba, conforme apresentado na figura 3.

Figura 3. Coexistência das atividades de pecuária bovina e arrendamento/parceria para cultivo da cana-de-açúcar na MRG de Ituiutaba

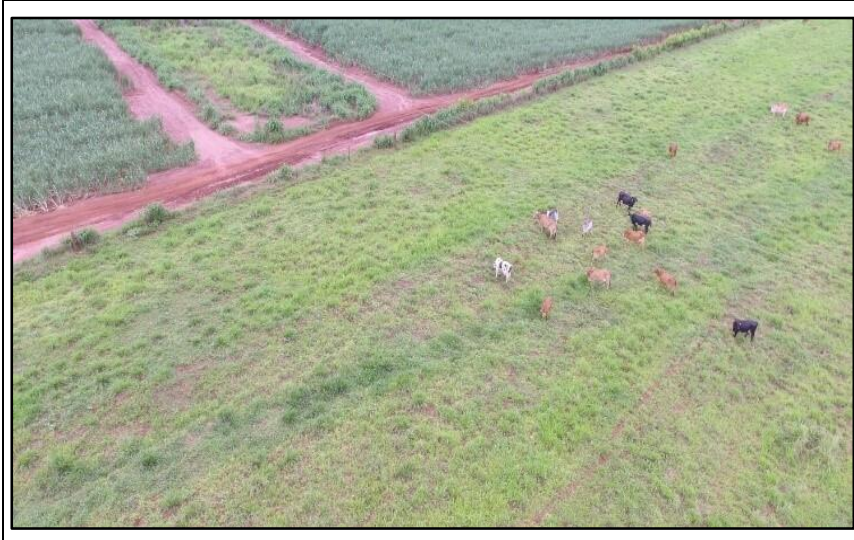

a)

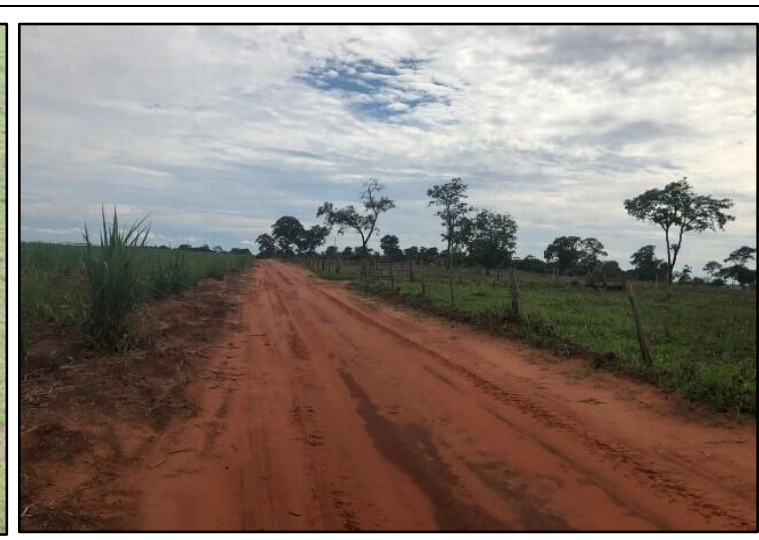

b)

Fonte: Penariol, R. Z. (2019).

Org. dos autores, 2021.

A foto a) mostra a atividade de pecuária bovina ao lado direto e, à esquerda, o cultivo de cana-de-açúcar praticado pela usina BP Bunge, registro realizado no município de Ituiutaba/MG; e a foto b) mostra a cana ao lado esquerdo e a pastagem à direita, produções desempenhadas no município de Santa Vitória/MG.

Pelo que pode ser observado em campo, cremos que a coexistência das atividades de pecuária bovina e o arrendamento/parcerias de terras para o cultivo de cana-de-açúcar decorre, em grande parte, da condição das chamadas "terras dobradas". A "terra dobrada", como comumente é denominada na região, corresponde a extensões em que imperam características de relevo acidentado, inviável, portanto, à realização da agricultura mecanizada. Trata-se de um limite natural à prática e expansão do cultivo moderno da cana-de-açúcar que, ao mesmo tempo, oferece condições de permanência e/ou coexistência da pecuária bovina tradicional.

Ronquim e Fonseca (2018, p. 13) apontam que o máximo de declividade do terreno para a colheita mecanizada da cana-de-açúcar é de até $12 \%$, assim, o cultivo moderno e mecanizado de cana torna-se inviável em declividades superiores a esta.

As propriedades marcadas pela presença das "terras dobradas", total ou parcialmente, não figuram como áreas de interesse para as usinas sucroenergéticas, permitindo a prática de outras atividades nesses espaços. Na MRG de Ituiutaba, os produtores têm utilizado a "terra dobrada" para o manejo da pecuária bovina (Figura 4), com a pastagem servindo de alimentação base para o gado. 
Figura 4. Área de terra dobrada em Ituiutaba

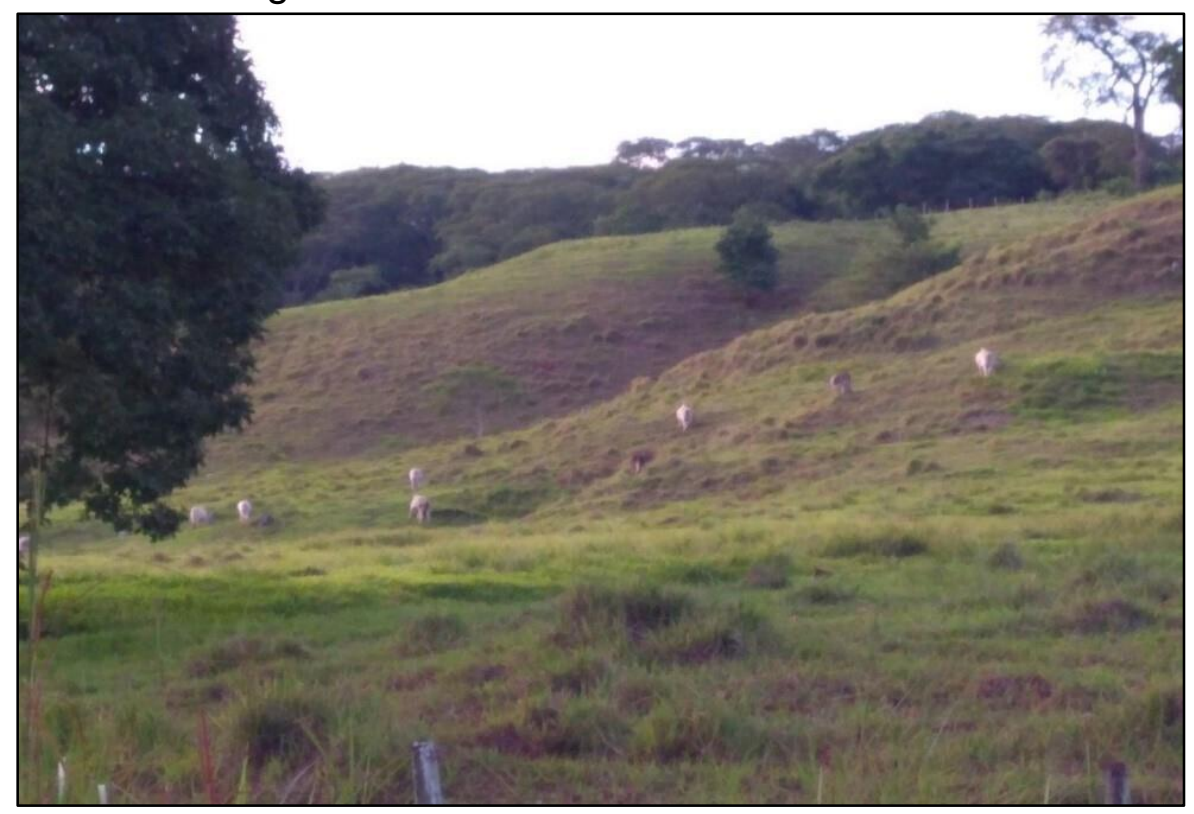

Fonte: Penariol, R. Z. (2019).

Conforme avaliamos, a expansão das atividades sucroenergéticas na MRG de Ituiutaba implicou em esquemas de deslocamento, substituição e coexistência nas práticas de pecuária bovina. Entretanto, em conformidade com sua tradição, percebese um significativo vínculo da região com a dinâmica de pecuária bovina, em parte hoje praticada a partir de técnicas modernas, mas também de algum modo sustentada por rugosidades espaciais, seja pelo tempo e tradição com que a pecuária bovina é realizada na região, seja pela presença de infraestruturas produtivas fixadas, como é o caso tanto de grandes frigoríficos (JBS) quanto de empresas que processam o leite (Nestlé, dentre outras), mas também em função das características físicas do território, onde a expansão da cana possui restrições (terras dobradas).

\section{CONSIDERAÇÕES FINAIS}

A formação e consolidação da MRG de Ituiutaba é em muito marcada pela presença da pecuária bovina, fato que confere à região certa identidade e função demarcadas na divisão territorial do trabalho. No entanto, a região também conhece, no século atual, uma significativa expansão do setor sucroenergético, afirmada pela inserção de três usinas sucroenergéticas e que resultou em algumas implicações sobre as estruturas pretéritas de uso do território.

Diante da expansão do setor sucroenergético sobre as atividades de pecuária bovina tradicional, identificamos três dinâmicas de inserção da cana na MRG de Ituiutaba: por deslocamento, por substituição ou ainda a coexistência. O deslocamento ocorre quando as atividades bovinas de baixo emprego técnico desenvolvidas na região, deslocam-se para outras regiões, especialmente para o Centro-Oeste (Goiás e Mato Grosso) e Norte (Tocantins e Pará). Assim, os proprietários de vastas porções de terra na região de Ituiutaba puderam estabelecer arrendamentos e/ou parcerias agrícolas com as usinas recém instaladas.

Também é evidente o processo de substituição, em que ao menos 210 propriedades de criação de gado (leite e corte) convertem suas atividades para o setor sucroenergético, o que representa $41 \%$ do total de propriedades atualmente voltadas 
para as práticas do setor. Em outros casos, proprietários rurais que detinham mais de uma propriedade concentraram suas atividades de pecuária bovina em uma única unidade e as demais propriedades foram destinadas ao cultivo de cana.

Além dos dois processos mencionados, como as práticas da pecuária também permanecem, a região é também marcada pela coexistência das atividades, em alguns casos numa mesma propriedade e, em boa parte dos casos, em propriedades vizinhas. A coexistência na mesma propriedade proporcionou a proprietários arrendarem e/ou estabelecerem parcerias agrícolas junto a usinas sucroenergéticas e, com tal alternativa de capitalização, investir na produção de uma pecuária bovina intensiva, aumentando índices de produção e a modernizando.

Em menor grau, evidenciamos a coexistência das atividades por limitações físicas da propriedade ("terra dobrada"), ou seja, os espaços das propriedades marcados por "terras dobradas" permanecem destinados para à prática de pecuária bovina, enquanto partes passíveis de mecanização agora são voltadas para as atividades sucroenergéticas.

O progresso cada vez maior do setor sucroenergético nas áreas de pastagens impulsionou uma produção de pecuária bovina em espaços menores no século atual, permitida por produtores capitalizados, que fazem o manejo do gado com 0 incremento de técnicas modernas, como a inseminação artificial, semiconfinamento e confinamento, suplementação alimentar, maquinários de alta performance, entre outros. Além disso, a produção da pecuária bovina é norteada por importantes agentes inseridos na região, como a Nestlé e JBS, que demandam quantidade elevada de matéria-prima, condicionando os proprietários capitalizados a incrementarem sua produção, visando atender tais necessidades dos agentes.

O desenvolvimento das atividades da pecuária bovina que permanece na região é sustentado, principalmente, pela presença dos sete agentes agroindustriais, a maioria instalado na segunda metade do século XX. Assim a permanência da prática de pecuária bovina é em parte garantida por rugosidades espaciais. Os agentes de atuação local/regional absorvem todas as escalas de produtores rurais (pequenos e médios) e agentes de expressão nacional e internacional (como é o caso da Nestlé) absorvem, via de regra, a produção realizada por médios e principalmente grandes produtores (também os mais capitalizados).

Por fim, é possível constatarmos que as atividades produtivas do setor sucroenergético e da pecuária bovina podem coexistir, gerando inclusive aporte de investimentos à pecuária, quando o pecuarista é capitalizado e em geral com maiores extensões de terra. De outro lado, a cana concorre e mesmo expulsa da região produtores descapitalizados (e sobretudo arrendatários), tornando-os assim mais vulneráveis, pelas próprias características intrínsecas à atividade e também ao engessamento do território que dela resulta.

\title{
REFERÊNCIAS BIBLIOGRÁFICAS
}

\author{
BARBOSA, W. de A. Dicionário histórico e geográfico de Minas Gerais. Belo \\ Horizonte: Itatiaia, 1995.
}

BRANDÃO, C. A. Triângulo: capital comercial, geopolítica e agroindustrial. 1989. 189f. Dissertação (Mestrado em Desenvolvimento e Planejamento Regional) Universidade Federal de Minas Gerais, Belo Horizonte, 1989. 
CASTILLO, R. Dinâmicas recentes do setor sucroenergético no Brasil: competitividade regional e expansão para o bioma Cerrado. Revista GEOgraphia, 17, № 35, 2015. Disponível em: http://www.geographia.uff.br/index.php/geographia/article/view/877. Acesso em: 06 maio 2018.

CHAVES, P. R. Evolução agrária do município de Ituiutaba (MG). Revista Acaiaca, Belo Horizonte, p. 43-48, 1971.

CLEPS JUNIOR, J. Dinâmica e estratégias do setor agroindustrial no Cerrado: o caso do Triângulo Mineiro. 1998. 316 f. Tese (Doutorado em Organização do Espaço) - Universidade Estadual Paulista "Júlio de Mesquita Filho" - UNESP, Rio Claro, 1998.

DATAVIVA. Dataviva - plataforma de dados/Minas Gerais. 2021. Disponível em: http://dataviva.info/pt/. Acesso em: 11 jan. 2021.

DATAVIVA/RAIS. Plataforma de visualização de dados sociais e econômicos do Brasil. Total de empregos municípios da MRG de Ituiutaba. 2021. Disponível em: http://dataviva.info/pt/build graph/rais/4mg0802/all/all?view=Employment\%20by\%20 Municipality\&graph=geo map. Acesso em: 05 jan. 2021.

DATAVIVA/SECEX. Plataforma de visualização de dados de comércio internacional. Exportações da Microrregião Geográfica de Ituiutaba. 2021. Acesso em: http://dataviva.info/pt/location/4mg0802/trade-partner. Disponível em: 17 jan. 2021.

DELGADO, G. C. Do capital financeiro na agricultura à economia do agronegócio: mudanças cíclicas em meio século (1965-2012). Porto Alegre: UFRGS, 2012.

ESTADÃO. BP compra produtora de etanol CNAA, em acordo de US\$ 680 milhões. Economia \& Negócios. Disponível em: https://economia.estadao.com.br/noticias/geral,bp-compra-produtora-de-etanol-cnaaem-acordo-de-us-680-milhoes-imp-,690868. Acesso em: 19 jan. 2021.

GUIMARÃES, E. N. Formação e desenvolvimento econômico do Triângulo Mineiro: integração nacional e consolidação regional. Uberlândia: EDUFU, 2010.

IBGE - Instituto Brasileiro de Geografia e Estatística. Censo Agropecuário de 1950. Rio de Janeiro: IBGE, 1950.

Censo Agropecuário de 1960. Rio de Janeiro: IBGE, 1960.

. Censo Agropecuário de 1970. Rio de Janeiro: IBGE, 1970.

Censo Agropecuário de 1975. Rio de Janeiro: IBGE, 1979.

Censo Agropecuário de 1980. Rio de Janeiro: IBGE, 1984.

Censo Agropecuário de 1985. Rio de Janeiro: IBGE, 1985. 

1959.

Enciclopédia dos municípios brasileiros: volume 25. Rio de Janeiro: IBGE,

Ministério do Planejamento, Orçamento e Gestão. Censo Agropecuário 2006. Brasil, Grandes Regiões e Unidades da Federação. Rio de Janeiro: IBGE, 2009. Disponível

em: https://biblioteca.ibge.gov.br/visualizacao/periodicos/51/agro 2006.pdf. Acesso em: 04 jan. 2021.

Recenseamento Geral de 1920. Rio de Janeiro: IBGE, 1920.

Recenseamento Geral de 1940. Rio de Janeiro: IBGE, 1950.

IMA - Instituto Mineiro de Agropecuária. Dados de estabelecimentos de pecuária bovina. Banco de dados da Regional de Uberlândia/MG. 2019.

LAPIG - Laboratório de Processamento de Imagens e Geoprocessamento. Atlas Digital das Pastagens Brasileiras. 2021. Disponível em: https://pastagem.org/atlas/map. Acesso em: 11 jan. 2021.

NOVAIS, A. S. História antiga de Ituiutaba. Ituiutaba - MG. 1974.

OLIVEIRA, H. C. M. de. Urbanizações e Cidades: análises da microrregião geográfica de Ituiutaba (MG). 2013. 431 f. Tese (Doutorado em Geografia) - Instituto de Geografia, Universidade Federal de Uberlândia, Uberlândia, 2013.

PENARIOL, R. Z. Coexistência das atividades de pecuária bovina e arrendamento/parceria para cultivo da cana-de-açúcar na MRG de Ituiutaba. 2019. 3 fotografia.

PENARIOL, R. Z. Área de terra dobrada em Ituiutaba. 2019. 4 fotografia.

PEREIRA, M. F. V. As atividades modernas da genética bovina no Brasil: funções e lógicas da especialização em Uberaba (MG). Boletim Goiano de Geografia, v.32, n.2, p.13-32, 2012a. Disponível em: https://www.revistas.ufg.br/bgg/article/view/21075/13495. Acesso em: 21 jan. 2021.

PEREIRA, M. F. V. Os agentes do agronegócio e o uso do território no Triângulo Mineiro/Alto Paranaíba: da moderna agricultura de grãos à expansão recente da canade-açúcar. Revista do Departamento de Geografia. v. 23, n.12, p.83-104, 2012b. Disponível em: https://doi.org/10.7154/RDG.2012.0023.0004. Acesso em: 21 jan. 2021.

RONQUIM, C. C.; FONSECA, M. F. Avanço das áreas de cana-de-açúcar e alterações em áreas de agropecuária no interior paulista. Campinas: Embrapa Territorial, 2018.

SIDRA - Sistema de Recuperação Automática. Produção Agrícola Municipal (PAM). 2021. Disponível em: https://sidra.ibge.gov.br/pesquisa/pam/tabelas. Acesso em: 12 jan. 2021. 
. Pesquisa da Pecuária Municipal (PPM). 2021. Disponível em: https://sidra.ibge.gov.br/pesquisa/ppm/quadros/brasil/2017. Acesso em: 12 jan. 2021.

SILVA, D. M. de O. Memória: lembrança e esquecimento. Trabalhadores nordestinos no Pontal do Triângulo Mineiro nas décadas de 1950 e 1960. 1997. 151f. Dissertação (Mestrado em História) - Pontifícia Universidade Católica, São Paulo, 1997.

SPAROVEK, G.; MAULE, R. F.; BURGI, R. Integração cana-pecuária: geração de valor social e ambiental. Visão Agrícola. N.8, jan/jun.2008, p.84-88. Disponível em: https://www.esalq.usp.br/visaoagricola/sites/default/files/VA08-ambiente05.pdf.

Acesso em: 30 jan. 2021.

VILELA, M. J. A agricultura e a pecuária de Ituiutaba nos últimos 50 anos. In: Fundação Cultural de Ituiutaba. O Centenário. Ituiutaba: Editora Gráfica, 2001. p. 8794. 